\title{
Trying to be someone you can never be again: retirement as a signifier of old age
}

\author{
SHLOMIT MANOR*
}

\begin{abstract}
Work occupies a central place in identity formation. Consequently, retirement places retirees in a new reality that compels them to redefine themselves and adopt a new identity. The present article examines how retirees shape their identity in the absence of work. An interpretive analysis of in-depth interviews conducted with retirees in Israel shows that although retirement and old age are not necessarily equivalent or interconnected, the retirees themselves draw parallels between them, and at the same time also deny this linkage, preferring to draw a distinction between them. The findings reinforce the argument presented in the literature, namely that in contemporary society it is difficult to identify with old age. They also propose a new perspective that reveals the negotiation retirees conduct with old age, age and body, and how identity is shaped by way of denial. In this negotiation the retirees construct their identity around two central, parallel axes: retirement and old age. It further emerges that it is precisely the efforts to mask and repress old age, which are usually made in the body domain, that attest to the existence and presence of old age in their identity. Denial of old age creates a dynamic, hybrid identity that enables retirees to simultaneously accept and reject old age.
\end{abstract}

$\boldsymbol{K E Y} \boldsymbol{W O R D S}$ - age, ageing, body, retirement, identity, hybrid identity.

\section{Introduction}

For many people, retirement, which constitutes a substantial change in life routines, represents a significant event and an important turning point. The perception of retirement as a new stage in life that mandates learning and reorganisation gave rise to numerous studies on the processes of adjusting to life after retirement (Atchley 1976; Barnes and Parry 2004; Sargent et al. 2012 ; Savishinsky 2000). The implications of retirement, which go way beyond the economic sphere and encompass additional spheres of life such as family, spousal relationships, society and leisure time, have also been extensively discussed in the literature (Dorfman 2002; Moen, Kim and Hofmeister 2001; Nimrod 2007; Szinovacz and Schaffer 2000). In

\footnotetext{
* Department of Sociology, Western Galilee College, Akko, Israel.
} 
contrast, the study of identity formation after retirement has been neglected and relegated to the margins of research, and only a few studies have addressed this issue (Barnes and Parry 2004; Price 2000; Sargent et al. 2012; Szinovacz and DeViney 1999). Since work is a key factor in an individual's identity in contemporary society (Beck 2002; Strasser 2003), the question is how do retirees define themselves in the absence of work? The present article will engage with the issue of identity after retirement by examining the place of old age in the identity of retirees. Consequently, the article will revolve around two main axes: retirement and old age.

In the past, retirement was virtually synonymous with old age and the final chapter in the cycle of life. Today, in light of the increase in life expectancy and due to technology, the gap between chronological and functional age is increasingly widening, making it difficult to define who is considered old and at what age old age begins (Hazan 2003b). Nevertheless, as Kaufman and Elder (2003) contend, people who have retired feel old and tend to link and draw parallels between old age and retirement. Moreover, once they have retired from the labour market, retirees are forced to contend with an achievement-oriented and competitive society that excludes and stigmatises the non-employed (Lundgren 2010; Sargent et al. 2012). Due to the difficulty in defining who is considered old, society employs external indicators in the body domain, such as hair colour, skin quality, clothes and functioning level, in order to determine who is old (Hazan 2003a).

Sociological discourse and research on identity have primarily focused on issues and questions associated with national, ethnic, racial, religious or gender identity, whereas age and old-age identity, especially that attending the retirement process, has been relegated to the margins of the debate and gained relatively little research attention. Nevertheless, the past two decades have seen an awakening of ageism research, and we are witnessing a growing number of studies on age and old-age identity. The literature discussing age identity ascribes considerable importance to age as an organising mechanism in our life, and to its uniqueness as being absolute and objective, yet also relative, changing and subjective (Hazan 1994, 2003b), and holding different meanings for different people (Hazan 2002; Kaufman and Elder 2002, 2003; Logan, Ward and Spitze 1992). Moreover, the research on identity in old age underscores the difficulty attending the acceptance of age identity and the attempts to repress age and old age (Barnhart and Peñaloza 2013; Day and Hitchings 2011; Gamliel 1999; Hazan 2010; Hurd 1999; Kaufman and Elder 2002; Weiss and Lang 2012; Whitbourne 1986), as well as the factors that alleviate acceptance of age (Kaufman and Elder 2003). The present article joins the literature discussing age and old-age identity, and seeks to examine how retirees conduct a negotiation with age, old age and the ageing body as part of their identity formation. 
The article will present a brief discussion on the centrality of work in contemporary society, followed by a review of studies discussing identity formation processes with reference to age and old-age identity. It will address the various reasons for its repression, including the phenomenon of ageism and the negative images ascribed to old people and old age, and the role of the body in identity as an additional means for resisting old age. After presenting the research methodology, and based on the findings obtained, the Discussion section will propose that age and old-age identity be discussed in the identity discourse in terms of hybridity, since despite efforts to deny it, it is indeed present.

\section{The significance of work in contemporary society}

Work has played and still plays a central role in determining an individual's identity as a factor that accords status and prestige, and constitutes a symbol of financial status and lifestyle (Beck 2002; Ben Israel 2000; Giddens and Held 1982; Gini 1998; Strasser 2003). Capitalist society translates success into material terms, and rewards and evaluates people according to their economic achievements. A capitalist economy, which typifies most Western countries, has brought about a situation whereby 'work' is primarily perceived as a means for making a living and as paid employment (Joyce 1989). In accordance with this approach, work is defined as an activity that is measured in time and rewarded with money (England and Harpaz 1990; Offe and Heinze 1992).

However, defining work solely as a means for making a living touches upon only one aspect of the meaning of work, and overlooks other meanings such as self-fulfilment and self-realisation, occupation, social status and belonging to a social group. Work contributes to the self-identity formation process, and many people define themselves through work, and are even labelled and recognised by others according to their occupation (Beck 2002). People gain social recognition due to their work, and it constitutes one of the factors that accord meaning to life (Giddens and Held 1982; Strasser 2003).

Work also constitutes a central component in identity due to the fact that a considerable number of an individual's adult years are spent at work (Price 2000). Whether an individual enjoys his or her work, succeeds or fails, work is part of the routine of his or her life (Giddens 1991; Gini 1998). In the absence of work, elderly people feel they are on the margins of society, and since they are non-productive they feel they have become a burden on productive society (Phillipson and Biggs 1998; Probert and Macdonald 1996). People who do not work, whether by choice or not (due to dismissal or retirement), find that they are lonely, 
and distanced and excluded from society due to loss of social connections (Strasser 2003).

In contrast, it has been argued that since the end of the twentieth century and the beginning of the 'Post-work Era' there has been an erosion of the status of work. Ideological changes and the transition from material to postmaterial values call the issue and centrality of work in an individual's identity into question (Inglehart and Abramson 1999). Proponents of this approach claim that technological development and changes in socio-economic conditions have shunted material values aside, and led to the strengthening of post-material values, such as self-fulfilment and self-realisation, freedom of expression, quality of life, ecology and environmental quality, or women's rights. While material values have not completely disappeared, the new reality has brought with it changes in priorities concerning the importance of certain values.

The vast body of literature on this subject presents different and contrasting approaches to the centrality of work in determining an individual's status and identity. The present study seeks to examine how the experience of retirement influences the identity formation process.

\section{Age identity construction}

In sociological thinking, identity is perceived as the product of social interactions in the course of which an individual sees him- or herself though others' eyes, and thus learns about him- or herself. An individual's identity is dependent upon the way he or she defines and positions him- or herself in relation to others and in relation to different social categories to which he or she belongs or does not belong. Consequently, identity is sociocultural context-dependent (Hall 1996; Hazan 1994; Kroger 2002; Rozario and Derienzis 2009).

The identity construction process is also influenced by the collectives to which an individual belongs, as well as those towards which he or she feels aversion and is not interested in belonging to. Thus, an individual can outline the boundaries between him- or herself and others. This process is the expression of the symbolic boundaries described by Lamont and Molnar (2002) that exist between 'us' and 'them'. Identities are based on people's tendency to classify themselves and others according to different categories such as age, class or nationality, and these classifications create group identities.

When speaking of dominant identities, or 'master identities' as Twigg (2009) calls them, then age is one of them, since it influences the individual's perception of themselves and of others. Old-age identity is how people perceive and present themselves to others in terms of age (Kaufman and Elder 2002; Logan, Ward and Spitze 1992; Rozario and 
Derienzis 2009; Weiss and Lang 2009). However, despite the subjective dimension, it is not detached from chronological age (Hazan 2002). The literature discussing age identity has primarily emphasised the stages and transitions between one age category and another, and the differences between age categories, e.g. young and mature people (Whitbourne 1986; Whitbourne, Sneed and Skultety 2002). Also discussed is the correlation between age identity and behavioural patterns and psychological characteristics such as personal wellbeing, satisfaction and self-image (Kaufman and Elder 2003; Logan, Ward and Spitze 1992; Westerhof and Barrett 2005). Additionally, the research addressed the question of universality in contrast with the cultural and social context of age identity (Barak 20o9; Barnhart and Peñaloza 2013; McCann et al. 2004). In the past two decades, the term 'age identity' has been primarily associated with old age (Rozario and Derienzis 2009; Schafer and Shippee 2009; Weiss and Lang 2012).

The way we perceive ourselves, and the changes that have occurred in the course of our life, as well as how others judge and catalogue us, derives to a large extent from our age (McCann et al. 2004; Nikander 2009; Settersten and Hagestad 1996). Consequently, age constitutes one of the accepted criteria for attributing social expectations to people, and accordingly the norms defining certain patterns of behaviour that are appropriate or inappropriate for other ages (Hazan 1994, 2003b; Logan, Ward and Spitze 1992). In contrast with other identities, such as gender, race, ethnicity or nationality, age is the only identity that constantly changes throughout life (Schafer and Shippee 2009; Weiss and Lang 2012). Thus, in the course of his or her life, an individual enters different, specific age categories, and adopts a new age-group identity each time anew.

Age identity is influenced by the social roles an individual performs in the course of his or her life, and by the stereotypes attached to these roles (Logan, Ward and Spitze 1992). A change in roles symbolises the transition from one age category to another, e.g. from the role of worker to that of retiree (Savishinsky 2000). For example, Kaufman and Elder (2003) found that becoming a grandparent has positive implications for an individual's age identity, whereas retiring actually has a negative impact on it. Since old-age identity is part of age identity, I shall now discuss the nature of this identity.

\section{Old age and 'non-old-age' identity}

The literature discussing old age and old-age identity generally emphasises the difficulties attending acceptance of old age as the dominant identity, and the attempts to repress and deny old age (Gamliel 1999; Hurd 1999; Lundgren 2010; Rozario and Derienzis 2009; Weiss and Lang 2009; Wilson 2009). One of the prevalent means of denying old age is manifested 
in employing alternative labels for 'elderly', such as 'senior citizens', 'golden years' or 'the third age'. These labels ostensibly soften the negative connotations associated with old age (Hazan 2002). Denial of old age is not only manifested in avoiding these labels, but also in avoiding using objects identified with old age, such as a walking stick, a hearing aid, a hot water bottle or a lap blanket (Day and Hitchings 2011).

Denial of old age is associated with the phenomenon of ageism. Butler (1969), who was the first to address ageism, defined it as prejudicial attitudes towards and a stereotypical perception of older people based solely on their age. There are many and varied manifestations of ageism, which is a widespread social phenomenon that violates human dignity, and is based solely on belonging to a particular age group (Doron 2011). Ageism is particularly evident in the labour market, due among other things to innovative technology that mandated new knowledge, skills and capabilities. Consequently, many employers prefer to employ young people rather than older ones, who are perceived as conservative and slow, and their experience does not constitute an advantage, but rather a disadvantage (Bodner 2oog).

The multitude of negative images and characteristics associated with old age compels older people to seek what Kaufman (1986) calls an 'ageless self' identity. To a certain extent a flexible, ageless identity enables the repression of chronological age and denial of old age (Biggs 1997; Day and Hitchings 2011; Hazan 2002, 2010; Kaufman 1986; Lomranz 1998; Rozario and Derienzis 2009; Wilson 2009). Moreover, as numerous studies claim, older people hold negative views and stigmas concerning old age to a greater degree than young people (Weiss and Lang 2009). Consequently, in order to reinforce their 'ageless' identity, older people tend to see themselves and present themselves as the continuation of who they were in their youth, and in the main continue to identify with their young self (Rozario and Derienzis 2009; Schafer and Shippee 2009).

Old age does not 'suddenly appear' at a particular or fixed age, and is, to a great extent, determined according to external images in the body domain (Hazan 2002; Lomranz 1998). Since an individual's identity is closely linked to his or her age and body (Biggs 1997; Hazan 2003a), the ageing, failing body becomes an indicator of old age. Thus, repression of old age makes the body, as the prominent indicator of old age, the principal arena in this battle, as will be discussed below.

\section{The presence of the body in old-age identity}

While engaging with the body is not considered a new phenomenon, in contemporary society the role of the body in identity formation has become 
increasingly central (Hazan 2003a), and preoccupation with body and weight has become almost obsessive (Clarke 2001; Hurd 1999). Numerous articles have been written on the role of the body, body image and its role in identity, but a considerable proportion of the research focuses on adolescents, young adults and adults (Oberg and Tornstam 2001), whereas research on the role of the body in old age was neglected, and only began to develop towards the end of the 2oth century (Hurd 2000; Kaminski and Hayslip 2006; Liechty and Yarnal 2010).

As a measure of old age, the body becomes the primary battleground for its repression, and the desired objective is to look young by delaying the symptoms of old age, and adopting a seemingly young identity (Biggs 1997; Oberg and Tornstam 2001). To this end, society markets disguises and young body images to older people in packages of anti-wrinkle creams, hair dyes, pills and even various types of plastic surgery (Hazan 2002, 2010). As a result, older people increasingly resemble people of younger ages, and behavioural patterns defined as normative for people in different age categories become increasingly blurred (Logan, Ward and Spitze 1992; McCann et al. 2004). This phenomenon is also manifested in the discourse which includes new concepts such as 'uni-age' or 'no-age women' (Oberg and Tornstam 2001).

As in many other spheres of life, here too there are double standards concerning how men and women are supposed to grow old and look (Sontag 1979). Women are perceived as ageing more rapidly than men, and the images associated with them are more negative than those associated with men (Biggs 1997; Clarke 2001; Hurd 2000; Kaminski and Hayslip 2006; Liechty and Yarnal 2010; Oberg and Tornstam 2001; Tiggemann 2004). Whereas external physical indicators attesting to age and old age are judged severely in women, who are primarily judged and evaluated by their appearance, men receive a relatively lenient and even favourable normative attitude. Since the female beauty ideal is identified with adolescent girls and young women, for most women being beautiful, attractive and successful means looking young (Clarke 2001; McMullin and Cairney 2004; Webster and Tiggemann 2003). Thus, in the struggle against the symptoms of old age men have a clear advantage over women, who find it difficult to preserve a young appearance (Hurd 200o), and age earlier than men (Kaminski and Hayslip 2006; Oberg and Tornstam 2001).

Based on the reviewed literature and research, the present study seeks to join the literature discussing age identity, by examining how retirement forms identity, and the degree to which old age is present in the identity of retirees in Israel. 


\section{Methods}

The present article is based on a qualitative study conducted between 2006 and 2008 with the aim of understanding the subjective meaning accorded to the experience of retirement and old age. Data were collected by means of semi-structured, in-depth interviews that facilitate a combination of preset questions and the flexibility and freedom to develop a dialogue with the interviewee during the interview. The interviews were held in the interviewees' homes, which provided an intimate setting and put the interviewees at ease. The interviews lasted between two and three hours.

The research population included 39 pensioners, 20 women and 19 men, aged $60-75$. This age range was chosen in order to gain an understanding of the retirement experience while it is still fresh in the interviewees' minds. Most of the interviewees are married and have children and grandchildren (with the exception of one widower and three divorcees). Although this was a small group, the heterogeneity of the interviewees was maintained in terms of their financial status, education and occupation, and included bus drivers, a fire fighter, production worker, teacher, school principal, physiotherapist, government ministry administrator, bank clerks, computer technicians, and so forth. The interviews were held individually without the presence of a partner or other family member.

The study employed the 'criterion sampling' method (Patton 1990), whereby the interviewees were selected in accordance with a central criterion: retirement from the labour market in the past decade. Additional criteria were also taken into account, such as age, marital status, occupation and financial status.

The interviewees were located using two principal methods: (a) Approaching various organisations such as the Haifa Seniors Lobby, or human resources departments and seniors clubs in large companies such as the Israel Electric Corporation or banks, which provided assistance in locating people who had retired in the past decade. Some interviews concluded with a recommendation to meet with other retirees, and thus additional interviewees were recruited using the 'snowball' method. (b) Approaching elderly people in public places such as bus and train stations, fitness centres, beach promenades, markets, shopping centres and cafés. I approached people who appeared to be within the suitable age range, struck up a conversation with them, and introduced myself and my study. If it transpired that they meet the criteria of having retired in the course of the past decade, I asked if they would agree to an interview, and if they did, we arranged to meet in their home at their convenience. 
The interviewees were asked questions about their experience of retirement, life in the absence of work, relationships with spouses and children after retirement, as well as questions about old age and ageing. It is important to note that at times it was the interviewees themselves who brought up the subject of the ageing body and the importance of maintaining physical fitness for their health, even though they were not asked either direct or indirect questions on this subject. Moreover, the issue of old age and death also frequently came up during the interview even though the interviewees were not asked about it.

\section{Analysis}

All the interviews were recorded and transcribed. After reading the transcriptions several times, I employed the stages of analysis suggested by Giorgi (1975) to identify recurrent themes, and built a profile for each interviewee. In the next stage I divided the interviews into categories in accordance with the themes that emerged. Following a cross-sectional reading of the interviews according to the categories, similarities and differences were identified between the interviewees, making it possible to compose broader categories. Thus, central themes were identified and constructed. This analysis method is consistent with the interpretive phenomenological approach, which enables an examination of experience and the subjective meaning accorded to it from the perspective of the person experiencing it (Creswell 1998).

\section{Ethics}

At the start of each interview, I emphasised that the interview was for research purposes only, I explained the aim of the interview, and assured the interviewees of anonymity and confidentiality. I also advised them that they could terminate the interview at any time, and that if they changed their minds during or after the interview, I would respect their decision and not make use of the material. All the quotes are presented with fictitious names so as not to divulge the interviewees' identities and to protect their privacy. The study was approved by the College Ethics Committee.

\section{Findings}

\section{'Getting up one day and there's nothing'}

Work provides people with a label and self-definition according to which they present themselves. After retirement, retirees are compelled to 
redefine themselves. For many of the interviewed retirees work constituted more than a source of income and occupation, but also a social framework that introduced content and interest into their life, and was part of their selfimage. They perceived their profession as a means for self-fulfilment and self-realisation irrespective of position, type of work or its standing on the prestige scale in the labour market. Liora, representing about 70 per cent of the sample, describes this experience as follows: 'Once you were somebody, even if just the cook or the gardener, but you were somebody, you had a role. Today you're nothing. That's my sadness ... You turn from somebody into just anybody ... If you no longer contribute to society, you're a burden on society'. Liora's words express a sense of emptiness. The absence of work makes her feel bereft of a social role and title. A person without an identity, without a profession and without work is 'just anybody', 'nothing'. Edna shares this feeling: 'Getting up one day and there's nothing is really hard. It's the first bell that rings. There are no phone calls at home'. The absence of work reinforces the retiree's feeling that he or she is useless and unneeded. Young society does not value accumulated experience and seniority as essential resources. Consequently, the experience of marginality intensifies and the feeling that non-employed people are unimportant to society, as Edna says: 'You feel that society has no need for you ... that the Moor has done his duty ... People make this gesture that it's passé, like I'm no longer in the picture, so why ask me or consult with me'.

The sense of emptiness is also articulated by Susan, who worked in a bank: 'It's very strange, I'm very sad, even though it was me who asked to retire, I could have continued working for three more years, but I didn't want to leave on a stretcher. But now I miss it, I miss it a lot. For a long time after I retired, for many months, I still dreamt about all kinds of things I did at the bank, about credits and debits'.

The sense of emptiness is exacerbated when retirement is imposed and unwanted, as Avri, who worked as a fire fighter, related: 'I didn't retire happily, in fact, I retired because I had to, not because I wanted to. I had to leave. So we spent the first year after retirement travelling, then you gradually start to fade ... it's a huge disappointment'.

The absence of work makes the retiree feel worthless since retiring from a position reduces the level of influence and the authority a person enjoyed when he or she worked. Dror articulates it as follows: 'You have to take into account that you'll have a lot more spare time, but you'll also be a lot less important ... The transition from you're important to you're not important, from you're busy to you're not busy. As soon as you stop going to work, you stop being important. Nobody's looking for you all that much, nobody needs you all that much'. 
Retirement strips retirees of their primary status, leaving them devoid of status, role and a basic component of their identity. The retirees, who for many years defined themselves through their work and profession, now have difficulty finding an alternative identity.

The picture is of course much more complex and is not one-dimensional, since alongside feelings of emptiness, loss and fear, retirement is also described in terms of freedom, liberation, and the absence of a binding and obligatory framework. Nearly 90 per cent of the interviewees used phrases such as 'I'm relaxed', 'I'm less stressed', 'I'm my own master', 'I'm on holiday' and 'retirement is like a blossoming spring' to describe retirement. However, it later transpires that in many cases the sense of liberation and infinite freedom remains an unfulfilled fantasy. The extensive free time is not utilised, it is threatening and frightening, and loneliness takes over, as Dean relates: 'At first it was a bit like a dream ... then came the terrible silence and the difficult mornings, and then comes the great fall'. Aaron shares this feeling, and says: There are a lot of dead hours in the day and I miss the company of my co-workers, sometimes I sit at home and wait for the time to pass'.

In effect, the retirees are speaking in two voices: one voice views retirement as an opportunity to follow their dreams, break free from the shackles of work, travel and relax, while the other describes emptiness, sadness and confusion, and at times helplessly facing the difficult task of introducing new content into this period of life. These two voices can be heard in Lena's words: 'On the one hand, feeling as free as a bird ... not having to answer to supervisors ... but, on the other, I have greater responsibility because I'm my own master now, and that requires a lot of discipline, not to deteriorate. When you're your own master and there's no one to organise your time for you, you have to see to it on your own, and that's a big responsibility ... It's part of retirement'.

\section{'Retirement as the end of life'}

Retirement is not identical with old age, and old age does not appear the moment a person retires from the labour market, and yet about 75 per cent of the interviewees tended to draw parallels between them and emphasise the linkage between retirement and old age, as Dafna's words illustrate: 'Naturally, the connection is a direct one. You usually retire when you reach what I call the final stretch of life. Uhm ... from this point forward you don't go to work, you're in fact waiting to die. The feeling is that after you retire you reach the final stretch of life, that's my definition of the matter'.

Thoughts about approaching death and time running out emerge in Aaron's words: 'At retirement age you start thinking about death ... you 
can't avoid it ... everything has its period, its time, when you get to the end you can retire ... I reached the end of the road, without shortcuts, so I retired'. Viewing retirement as the 'final stretch of life' stems among other things from the perception that once a person stops working he or she stops being productive and of value, and is in effect approaching death, as Rafi describes: 'It's said that when a person retires he ages rapidly ... If it's hard for a person without work, then he should find a part-time job or volunteer work to fill the gap'. Rafi's words reinforce the perception that in the absence of work, old age takes over. Dafna links and draws parallels between retirement and old age, and adds: 'I presume the third age is from the day of retirement, which usually begins at 60 or $6_{5}$ or 67 , till the day you die, because once you stop working and doing things your skills gradually deteriorate ... your physical abilities deteriorate'.

The parallels between retirement and old age also emerge in Susan's words: 'There's a connection between retirement and old age, there's a connection, because some people, as soon as they retire they become old, but not all of them, some people stay the same and try to be young at heart'. Like other interviewees, Susan draws a connection between retirement and old age, but immediately separates them and qualifies her words by saying 'not all of them', and in effect negotiates with the linkage she herself creates.

It is worthy of note that the subject of death was not broached in the interviews, neither directly nor indirectly, and it was the interviewees themselves who linked and drew parallels between retirement, old age and death as events that occur in close proximity, at times by way of denial, as Dean relates: 'You retire from work, you don't have to retire from life as well'. However, the very fact of speaking by way of denial and the attempt to separate 'retirement from work' from 'retirement from life' and old age attests to the degree to which it is present, since if it did not exist in their consciousness they would not speak of it so extensively, and it would be absent from the discourse.

\section{'Retirement and old age are way-stations'}

The retirees conduct an ongoing negotiation with old age, which exists in their consciousness. They talk about it, are afraid of it, avoid it, see and do not see it, and it is constantly present in their interviews. However, the array of negative stereotypes characterising old age and old people contributes to the construction and consolidation of an identity by way of denial. Yet it is precisely the efforts to avoid the title 'old' and the proximity of old people which attest to the opposite, to the extent to which it is fully present and influences the identity formation process. The interviewed retirees do not call themselves 'old', but are aware of its existence. Ron, 
for example, defined it as follows: 'It's hard for a person to say, I'm old ... although I do know I'm old, but deep down I don't feel that I'm old. I don't know how to explain it, but going by what I hear from others, no one feels that way, right? But we all know we've reached that age'.

Despite employing a variety of strategies to repress old age, they are all well aware of their age, but old age is not perceived in terms of age. They avoid seeing themselves as old people because they claim they do not feel their age, and consequently for them old age is not linked to age. However, it is precisely the various repression practices that attest to the extent to which age and old age are present in their consciousness, as related by Rachel: 'In two weeks I'll be 73 . Believe you me, I have to remind myself of this. I don't believe it. It's not me ... If you don't feel yourself old, and you don't broadcast that you're old, then you're not old. I really don't feel old, you see, I know I'm 73, I get more tired, and I get pains here, but inwardly I feel myself young'.

Another strategy employed to repress and negotiate with old age is to employ humour, as related by Anna: 'Of course there's a connection between retirement and old age, look, I always say that I've got no problem with memory, my only problem is forgetting ... and it's very complicated and difficult in secretarial work ... that's why we started doing crosswords, to preserve memory'.

Social identities are based on people's tendency to classify themselves and others according to a system of different social categories, and these classifications consequently create a distinction between 'us' and 'them'. Retirees, who are identified with a particular age group, do not want to belong to an age-based social category since this reference group is undesirable to them. Thus, for example, they do not want to travel with other retirees, or to sit in a club with them, and avoid spending time with people of their age. Noah expressed it as follows: 'Children like other children of their own age, old people don't ... In the company of old people, you're reflected. You're not young any more ... There's something unpleasant in the company of old people'.

However, despite their attempts at repression, they are preoccupied with the question of how others see and perceive them. On this matter Noah says: 'I don't feel limited in anything I do, I can work in the garden, and I can carry heavy loads. But I always wonder what other people see in me'. This reflection, as Noah calls it, forces them to face reality, but since this reality is unwanted, they are forced to manoeuvre and maintain a vague age identity that lacks a clearly defined age category.

The question of how they are perceived by their environment is meaningful to them since it is liable to form cracks in the non-old-age image they 
seek to build for themselves, as Ariell says: 'I know that that's the attitude of the environment towards retirees'.

The interviewees' words illustrate the negotiation conducted by retirees with reference to their age and old age with all its attendant images. Despite its repression, they ultimately acknowledge that old age is stronger than them, and is in fact already here, very close, as Noah stated: 'There are way-stations along the way that you know you have to pass. You get your pay slip and you're a pensioner. People address you like a senior citizen ... Retirement and old age are way-stations and it can stop at any moment'.

\section{'You have to invest in the old and worn-out body'}

The linkage between retirement and old age is also manifested in the body domain, and introduces another dimension into the discourse on identity after retirement, as emerges from Paul's words: 'Since I retired, it may be a coincidence, it may be psychosomatic, I don't know, but I'd never been to see a doctor before, and since I retired all of a sudden I need glasses, and I don't know if it's connected, but I found this tumour on my leg that had to be removed ... it happened close to my retirement but maybe it's not connected, maybe it's just a coincidence'.

Since the body constitutes a tangible measure of old age, the retirees can fight against the very linkage they themselves create between retirement and old age, for in the body domain it is ostensibly possible to fight and prevent the physical indicators of old age, and thus delay the visibility of old age. About 70 per cent of the retirees in the sample believe that changing their lifestyle, including changing their diet, diverse physical activities in fitness centres, swimming in a pool or the sea, and walking, will guarantee health and protect them against old age, and thus they will be able to postpone their entry into this stage in life, as Liat's words indicate: 'Knowing that you're doing everything you can, because otherwise you'll say I could have done something and maybe it wouldn't have happened to me, and I didn't. And statistically, and according to research, everybody says definitely exercise, and physical activity, and eating correctly, swimming, can make a difference'.

Avri, too, claimed that because he engages in sport his health improved so much so that he no longer needs to take medication to lower his blood sugar: 'Shape [fitness centre] helps me a great deal. I look after myself. I feel better, Shape helped me because I work out and burn off the sugar'.

The retirees' attempts to maintain the standards of a young and healthy body dictate a variety of practices in order to adapt themselves to this image. From taking pills, vitamins, minerals and hormones, through engaging in sport and exercises designed to preserve flexibility, to cosmetic treatments, plastic surgery, various diets and anti-ageing therapies, all for the purpose of 
preserving and maintaining the body. With these and other diverse means, they can attempt to blur their chronological age. The monologue Ronit conducts with her body in front of the mirror can be heard in the following quote: 'I don't preoccupy myself with how I look, and I'll never consider plastic surgery or anything like that, it's not that I don't look at myself in the mirror, or see myself and say, "Is that me?" You know, the usual things, but it does take me to this thing that you do need to look after yourself, and I go to the gym and force myself to go at least once or twice a week'.

Ronit is speaking in two voices. On the one hand, she claims that her appearance is not important to her, and on the other, she examines herself in the mirror. The physical activity at the gym symbolises the yearning for a body that no longer exists, and expresses the difficulty of accepting and coming to terms with the flaccid, ageing body as it is. At the end of the interview, on her way to the gym, Ronit said: 'It's something you have to do once a week, I know I have to invest in my worn-down body in order to continue doing what I'm doing, and it's part of hygiene. There's nothing to be done, I'm body-dependent. We're body-dependent'.

Despite the belief that physical activity contributes to health, some of the interviewees attest that they do not enjoy the activity, but consider it mandatory, something that has to be done, as Tzila describes: 'Once a week I exercise ... I know it's important, that I have to do it, and I go once a week, I'm strict about that, and it's enough for me. Some people go and turn it into a religion, every day. I do enough, it's enough for me'.

Like Tzila, Rachel relates that even though she had never enjoyed sport activity she took up sport classes because she was persuaded that it was important. She describes it as follows: 'I never liked exercising and I never thought to exercise, but how did I get into it ... they told me, "Come and give it a try", and it's really amazing because I was never even prepared to hear anything about exercising, and here I am... one morning a week'.

The double standards regarding what men and women should look like in old age are also manifested in the different meaning accorded to the body, and in the motivations for physical activity. For example, women attend exercise classes in order 'to invest in the body', to maintain flexibility, prevent back pains and to look good. In contrast, men primarily view engaging in the different sports as an opportunity for social encounters, as Shimon attests: 'I go bowling once a week with one bunch of friends, and once a week with another bunch of friends, so that's twice a week'.

Thus, engaging in sport helps to alleviate boredom and loneliness, and especially to feel a sense of belonging, in this instance to a sport club, as Rafi relates: 'If you belong to a club that's good as well. It's also one of the objectives, that if you can't connect with people then you come to the country club where you've got activities, classes, something to do'. At times engaging in 
sport serves as a means to pass the time, as Rami explained: 'I've never held a ball myself, which is why I say you've got to fill up the time'.

Although the need to look after the body was raised in interviews with other men as well, it was primarily for the purpose of maintaining health, 'the dream is to be healthy' or 'the main thing is a healthy body', and I did not hear anything from them about the need to be attractive, or reference to physical appearance, or disappointment with the ageing body.

\section{Discussion: old age as engendering a hybrid identity}

Retiring from the labour market is not necessarily identical with old age and its various attendant meanings, yet the narrative emerging from the interviews reflects a different experience wherein a complex correlation exists between retirement and old age. The story the retirees tell is one of people who feel that from the moment they retired from the labour market they became old people who refuse to be old. It is the story of healthy people speaking about fears of falling ill, growing old and dying. Paradoxically, the retirees themselves create the linkage and draw parallels between old age and retirement, but at the same time also display strong resistance to the connection they themselves have made. Thus, the retirees create an ambivalent experience with which they live and which they attempt to reconcile by denying and repressing old age. It further emerges from the findings that the status of work does not diminish. It transpires that work still constitutes the primary nucleus in determining a person's identity, and that the void that opens up once it disappears is filled with an old-age identity, with emptiness, and with a sense that time is running out and life is about to end.

Negative images are attached to old age and old people, whereas the prevalent image of youth and early adulthood is filled with grace and charm. In this reality it is difficult to grow old and look old. This results in rejection of indicators of old age that can be denied, and a search for alternative identities. Consequently, an old person's 'non-old-age' and 'ageless' identity is shaped by way of denial in a long and protracted process typified by constant negotiations. The individual examines him- or herself in relation to desirable and undesirable others, and contends with mixed emotions concerning components of his or her identity, such as rejection and acceptance, aversion and coming to terms. However, it is precisely the focus on the body as an indicator of approaching old age that enables repression, since the ability to deny or emphasise old age in fact centres on the body.

For the purpose of including age and old-age identity in the identity discourse, I shall borrow the term 'hybrid', which has thus far been discussed in other contexts, and is identified with post-colonial theories. The 
concept of hybridity enables reference to the meaning of identity in way that is not essentialist or binary, and describes the formation of a multi-layered identity containing an admixture or collage of identities that can at times contradict one another (Bhabha 1994; Hall 1996). Relocating the concept of hybridity from the post-colonial to the old-age discourse enables an examination of the issue of identity formation not only around questions of colour, race or class, but also around the question of age, with reference to the complex relationship between the world of the young and that of retirees. The identity of retirees is hybrid, and contains segments of identities from the past and present, such as a professional, grandparental, old-age or pensioner identity, and all that they entail. This complexity is manifested in the fact that they identify with some identity segments, and recoil from others. Their complex attitude towards their age and body constitutes an example of this hybrid identity.

The retirees' ambivalent attitude towards the categories and social groups to which they belong, either willingly or reluctantly, as well as their ambiguous attitude towards age, body and old age, engender an identity replete with contradictions. Like the black slave trying to imitate and resemble his white master in Frantz Fanon's Black Skin, White Masks (1952), thus pensioners make efforts to resemble young people, and do everything they can to avoid belonging to pensioners groups or be identified with old age and old people. Permit me to borrow the term 'imitate' from Fanon's thinking, and use it in a different content world in order to establish and illustrate this argument. It is precisely in their attempts to imitate the body and appearance of working, exercising, upright, healthy young people that the ageing retirees in effect deny themselves the right to be themselves and accept themselves as they are. Repressing old age by struggling against the body and efforts to look young make it difficult for them to accept themselves and form a self-identity. The retirees' imitation of the image of the working young in effect creates a hybrid, since it is clear that the retirees are not young, but in their own eyes they refuse to be old. This is what Fanon calls a hybrid subject, not yet white, but no longer completely black. Thus, the retiree organises his or her identity by determining the boundaries between 'I', 'us' and 'them', and marks for him- or herself the similarities or differences that separate and differentiate, and what is desirable or undesirable to him or her.

The retirement discourse as it emerges from the interviews is typified by a repertoire of narratives expressing the retirees' identity formation as they struggle between denial and acceptance, and consequently their identity is multifaceted. This reality, which enables them to hold several identities, even if they are not consistent with chronological age, ostensibly allows them to be ageless and hold a 'non-old-age' identity. This situation often creates conflict with other identities, and at times internal contradictions, 
when an individual can simultaneously perceive him- or herself as 'old' and 'not old', either temporarily or permanently. Thus, age identity becomes relative, subjective, dynamic and changing from time to time.

The blurring of age identity boundaries is manifested in older people today being able to shape an ageless identity for themselves that does not adhere to establishment criteria, thus creating a seeming closeness and resemblance between young and old people (Biggs 1997). As a result, more people are less suitable for classification according to normative age criteria, which until now typified the period of retirement and old age (Biggs 1997; Phillipson and Biggs 1998). However, it is precisely the efforts to resemble young people by adopting a 'non-old-age' identity that attest to the extent to which old age occupies a central place. Despite repression attempts, it seems that old age exists in its full force in their consciousness, and constitutes part of the negotiations entailed in constructing identity in this period of life. Repressed and repelled old age exists precisely in those who try with all their might to ignore it.

In the present study, I sought to examine how people who have retired from the labour market converse with old age, the body and age, and how the experience of retirement and absence of work affects their identity formation. To date, the period of retirement and absence of work have not been researched in the context of its implications for age and old-age identity in Israel, and thus the present study is innovative in its field. In this respect, borrowing the concept of hybridity from a different content world and introducing it into the world of retirement and old age constitutes a conceptual contribution to the discourse on retirement. Thus, it contributes to the understanding concerning the complexity of the multifaceted identity that is shaped and exists in a structural and cultural power system which is stratified, among other things, in terms of age.

\section{Acknowledgement}

The author wishes to thank Dr Nitza Berkovitch for her useful comments during the various stages of this research.

\section{References}

Atchley, R. C. 1976. The Sociology of Retirement. Schenkman, Cambridge.

Barak, B. 2009. Age identity: a cross-cultural global approach. International Journal of Behavioral Development, 33, 1, 2-1 1 .

Barnes, H. and Parry, J. 2004. Renegotiating identity and relationships: men and women's adjustments to retirement. Ageing E Society, 24, 2, 213-33. 
Barnhart, M. and Peñaloza, L. 2013. Who are you calling old? Negotiating old age identity in the elderly consumption ensemble. Journal of Consumer Research, 39, $6,1133-53$.

Beck, U. 2002. A Beautiful New World: A Model for Civil Society. Hakibbutz HameuchadKav Adom Series, Tel Aviv, Israel. (Hebrew translation)

Ben Israel, R. 200o. Social justice in the post-industrial era: distributive justice in the division of work. In Maunter, M. (ed.), Distributive Justice in Israel. Ramot-Tel Aviv University, Tel Aviv, Israel, 309-40. (In Hebrew).

Bhabha, H. K. 1994. The Location of Culture. Routledge, London.

Biggs, S. 1997. Choosing not to be old? Masks, bodies and identity management in later life. Ageing $\mathcal{E}^{2}$ Society, 1 7, 5, 553-70.

Bodner, E. 2009. On the origins of ageism among older and younger adults. International Psychogeriatrics, 21, 6, 1003-14.

Butler, R. 1969. Age-ism: another form of bigotry. The Gerontologist, 9, 3, 243-6.

Clarke, L. H. 2001. Older women's bodies and the self: the construction of identity in later life. Canadian Review of Sociology and Anthropology, 38, 4, 441-65.

Creswell, J. W. 1998. Qualitative Inquiry and Research Design: Choosing Among Five Traditions. Sage Publications, Thousand Oaks, California.

Day, R. and Hitchings, R. 2011 . Only old ladies would do that: age stigma and older people's strategies for dealing with winter cold. Health EF Place, 17, 4, 885-94.

Dorfman, L. T. 2002. Retirement and Family relationships: an opportunity in later life. Generations, 26, 2, 74-9.

Doron, A. 2011 . Ageism and anti-ageism in Supreme Court rulings. Hamishpat, 14, $65^{-126 . ~(I n ~ H e b r e w) ~}$

England, G. W. and Harpaz, I. 1990. How working is defined: national contexts and demographic and organizational role influences. Journal of Organizational Behavior, $\mathbf{1 1}, 4,253-66$.

Fanon, F. 1952. Black Skin, White Masks. Grove Press, New York.

Gamliel, T. 1999. The lobby as an arena in the confrontation between acceptance and denial of old age. Journal of Aging Studies, 14, 3, 25 $5^{1-71}$.

Giddens, A. 1991. Modernity and Self-identity: Self and Society in the Late Modern Age. Polity Press, Cambridge.

Giddens, A. and Held, D. (eds) 1982. Classes, Power, and Conflict: Classical and Contemporary Debates. University of California Press, Berkeley, California.

Gini, A. 1998. Work, identity and self: how we are formed by the work we do. Journal of Business Ethics, 17, 7, 707-14.

Giorgi, A. 1975. An application of phenomenological method in psychology. Duquesne Studies in Phenomenological Psychology, 2, 82-103.

Hall, S. 1996. Introduction: Who needs identity? In Hall, S. and Du Gay, P. (eds), Questions of Cultural Identity. Sage, London, 1-17.

Hazan, H. 1994. Old Age: Constructions and Deconstructions. Cambridge University Press, Cambridge.

Hazan, H. 2002. Aging in the global village. In Brik, Y. (ed.), Politics of Old Age. Hakibbutz Hameuchad, Tel Aviv, Israel, 30-50. (In Hebrew)

Hazan, H. 2003a. The body sociological: on the status of somatic representation. Israeli Sociology, 5, 1, 219-30. (In Hebrew)

Hazan, H. 2003 b. Anthropology of aging. In Rosin, A. (ed.), Aging and Gerontology in Israel. Eshel Press, Jerusalem, 575-14. (In Hebrew)

Hazan, H. 2010. Anthropologist on Mars: Invitation on the dead-end labyrinth of old age studies. Gerontology, 37, 1, 23-35. (In Hebrew)

Hurd, C. L. 1999. 'We're not old': older women's negotiation of aging and oldness. Journal of Aging Studies, 13, 4, 419-39. 
Hurd, C. L. 200o. Older women's body image and embodied experience: an exploration. Journal of Women and Aging, 1 2, 3/4, 77-97.

Inglehart, R. and Abramson, P. R. 1999. Measuring post materialism. American Political Science Review, 93, 3, 655-77.

Joyce, P. 1989. The Historical Meanings of Work. Cambridge University Press, Cambridge.

Kaminski, P. L. and Hayslip, B. 20o6. Gender differences in body esteem among older adults. Journal of Women Eं Aging, 18, 3, 19-35.

Kaufman, G. and Elder, G. H. 2002. Revisiting age identity. Journal of Aging Studies, $\mathbf{1 6}, 2,169-76$.

Kaufman, G. and Elder, G. H. 2003. Grandparenting and age identity. Journal of Aging Studies, 17, 3, 269-82.

Kaufman, S. R. 1986. The Ageless Self: Sources of Meaning in Late Life. University of Wisconsin Press, Madison, Wisconsin.

Kroger, J. 2002. Identity processes and contents through the years of late adulthood. Identity: An International Journal of Theory and Research, 2, 1, 81-99.

Lamont, M. and Molnar, V. 2002. The study of boundaries in the social sciences. Annual Reviews of Sociology, 28, 1, 167-95.

Liechty, T. and Yarnal, C. M. 2010. The role of body image in older women's leisure. Journal of Leisure Research, 42, 3, 443-67.

Logan, J. R., Ward, R. and Spitze, G. 1992. As old as you feel: age identity in middle and later life. Social Forces, 71, 2, $45^{1-67}$.

Lomranz, J. 1998. An image of aging and the concept of integration: coping and mental health implications. In Lomranz, J. (ed.), Handbook of Aging and Mental Health. Plenum, New York, $217-54$.

Lundgren, A. S. 2010. In the good old days: insidious nostalgia and the constitution of old age identity. Journal of Aging Studies, 24, 4, 248-56.

McCann, R. M., Kellermann, K., Giles, H., Gallois, C. and Viladot, A. M. 2004. Cultural and gender influences on age identification. Communication Studies, 55, $1,88-105$.

McMullin, J. A. and Cairney, J. 2004. Self-esteem and the intersection of age, class and gender. Journal of Aging Studies, 18, 1, 75-9o.

Moen, P., Kim, J. E. and Hofmeister, H. 2001. Couples' work/retirement transition: gender and marital quality. Social Psychology Quarterly, 64, 1, 55-71.

Nikander, P. 2009. Doing change and continuity: age identity and the micro-macro divide. Ageing $\mathcal{E}^{2}$ Society, 29, 6, 863-81.

Nimrod, G. 2007. Retirees' leisure activities, benefits and their contribution to life satisfaction. Leisure Studies, 26, 1, $65-80$.

Oberg, P. and Tornstam, L. 2001. Youthfulness and fitness: identity ideals for all ages? Journal of Aging and Identity, 6, 1, $15^{-29}$.

Offe, C. and Heinze, R. G. 1992. Beyond Employment. Polity Press, Cambridge.

Patton, M. Q. 199o. Qualitative Evaluation and Research Methods. Sage, Newbury Park, California.

Phillipson, C. and Biggs, S. 1998. Modernity and identity: themes and perspectives in the study of older adults. Journal of Aging and Identity, 3, 1, 1 1-23.

Price, C.A. 200o. Women and retirement: relinquishing professional identity. Journal of Aging Studies, 14, 1, 81-101.

Probert, B. and Macdonald, F. 1996. The Work Generation: Work and Identity in the Nineties. The Future of Work Project, Brotherhood of St. Laurence, Melbourne.

Rozario, P. A. and Derienzis, D. 2009. So forget how old I am. Sociology of Health $\mathcal{E}^{\circ}$ Illness, 31, 4, 540-53. 
Sargent, L. D., Lee, M. D., Martin, B. and Zikic, J. 201 2. Reinventing retirement: new pathways, new arrangements, new meanings. Human Relations, 66, 1, 3-21.

Savishinsky, J. S. 2000. Breaking the Watch: The Meaning of Retirement in America. Cornell University Press, Ithaca, New York.

Schafer, M. H. and Shippee, T. P. 2009. Age identity gender and perceptions of decline: does feeling older lead to pessimistic dispositions about cognitive ageing? Journals of Gerontology: Social Sciences, $\mathbf{6}_{5} \mathbf{B}, \mathbf{1}, 91-96$.

Settersten, R. A. and Hagestad, G. O. 1996. What's the latest? Cultural age deadlines for family transition. The Gerontologist, $\mathbf{3 6}, \mathbf{2}, 178-88$.

Sontag, S. 1979. The double standard of aging. In Williams, J. (ed.), Psychology of Women. Academic Press, San Diego, California, 462-78.

Strasser, J. 2003. When the Working Society Runs Out of Work. Hakibbutz HameuchadKav Adom Series, Tel Aviv, Israel. (Hebrew translation)

Szinovacz, M. E. and DeViney, S. 1999. The retiree identity: gender and race differences. Journal of Gerontology: Social Sciences, 54B, 4, S207-18.

Szinovacz, M. E. and Schaffer, A. M. 2000. Effects of retirement on marital conflict tactics. Journal of Family Issues, 2 1, 3, 367-89.

Tiggemann, M. 2004. Body image across the adult life span: stability and change. Body Image, 1, 1, 29-41.

Twigg, J. 2009. Clothing, identity and the embodiment of age. In Powell, J. and Gilbert, T. (eds), Aging Identity: A Dialogue with Postmodernism. Nova Science Publishers, New York, 93-104.

Webster, J. and Tiggemann, M. 2003. The relationship between women's body satisfaction and self-image across the life span: the role of cognitive control. Journal of Genetic Psychology, 164, 2, 241-8.

Weiss, D. and Lang, F. R. 20o9. Thinking about my generation: adaptive effects of a dual age identity in later adulthood. Psychology and Aging, 24, 3, 729-34.

Weiss, D. and Lang, F. R. 2012 . The two faces of age identity. GeroPsych, 25, 1, 5-14.

Westerhof, G.J. and Barrett, A. E. 2005. Age identity and subjective well being: a comparison of the United States and Germany. Journals of Gerontology: Social Sciences, 6oB, 3, 129-36.

Whitbourne, S. K. 1986. The Me I Know: A Study of Adult Identity. Springer-Verlag, New York.

Whitbourne, S. K., Sneed, J. R. and Skultety, K. M. 2002. Identity processes in adulthood: theoretical and methodological challenges. Identity: An International Journal of Theory and Research, 2, 1, 29-45.

Wilson, G. 2009. 'Not old' and 'old': postmodern identities in a new life stage. In Powell, J. and Gilbert, T. (eds), Aging Identity: A Dialogue with Postmodernism. Nova Science Publishers, New York, 69-79.

\section{Accepted I7 December 2015; first published online I 8 February 2016}

Address for correspondence:

Shlomit Manor,

Department of Sociology,

Western Galilee College,

Akko, Israel

E-mail: Manor.shlomit@gmail.com 